Jaromir Siroky - Katarina Magdechova - Petr Nachtigall - Stephan Schroder - Pavlina Siroka

\title{
IMPLEMENTATION SYSTEM OF TECHNICAL SPECIFICATION FOR INTEROPERABILITY FOR THE ROLLING STOCKS
}

In the paper, the present state of scientific knowledge in authorising the types of railway vehicles in Slovakia and abroad is analysed by the authors. The aim of the authorisation of the types of railway vehicles is to take into account the interests of the whole society in the field of transport in the manufacturing of these vehicles or their import from abroad. These interests mainly include a greater security of transport, as well as a greater quality, reliability and lifespan of railway vehicles. The authors also analyse the Commission Recommendation 2014/89\%/EU of 5 December 2014 on matters related to the placing in service and use of structural subsystems and vehicles under Directives 2008/5\%/EC and 2004/49/EC of the European Parliament and of the Council, which should contain instructions related to the matters in question. At the same time, it is necessary to take into account Directive (EU) 2016/797 of the European Parliament and of the Council of 11 May 2016 on the interoperability of the rail system within the European Union, and Directive (EU) 2016/798 of the European Parliament and of the Council of 11 May 2016 on the railway safety. In addition to ensuring the applicability of interoperability regulations (new directives, regulations, decisions, recommendations, etc.), the aim of this paper is to present a methodology of authorising the types of railway vehicles and a software model (SW) of authorising the types of railway vehicles, with European legislation as a possible tool to speed up and simplify the entire process. The paper is concluded by three types of authorisation processes for different railway vehicles and their accessories, comparing the length and complexity of processing using the standard authorisation process and using the $S W$ tool proposed.

Keywords: Single European Area, interoperability, methodology of authorisation type of vehicles, software model, authorisation type of vehicles, TSI

\section{Introduction}

The main task of the authorisation process of the vehicles types is to attract wider interest of the public in production and import in the area of transport. It mainly applies to safety but also to ensuring the quality, reliability and lifecycle of the rolling stocks at the required level. These requirements need to be met and at the same time they should be a tool to satisfy transport needs. The vehicles should reflect the progress in science and technology and their construction should be in harmony with the development of transport [1-2].

Achieving the aims of interoperation within the spectre of the rail system in the European Union should result in setting up the optimal level of technical harmonization and mitigate, improve and further develop services that are offered within international railway transport [3]. The aim is to create an inner market with facilities and services targeting at building, innovation, modernization and operation of the rail system in the Union. Within the fourth railway packet, a new procedure is proposed of authorising a new type of railway vehicles and placing them in service. The aim is to transfer the competences of authorising and certifying the types of railway vehicles to the European Union Agency for Railways (EUAR) [4]. Individual activities should be carried out on the basis of dividing the competences between the EUAR and the National Safety Authority (NSA). Objective activities will be carried out on the basis of the legal relationship between these two bodies. Fundamental is the elimination of national regulations and direct exercisability of technical specification for interoperability (TSI) as internal regulations for the entire railway network [5].

\section{Theoretical background}

Authorising the types of railway vehicles is an integral part of the transport process. The main goal should be securing the safety of transport. The aim of every authorising body is to ensure that the authorisation process is carried out in accordance with the European legislation and in a non-discriminatory way [6].

Development of authorising the types of railway vehicles has gone through several changes since the

\footnotetext{
Jaromir Siroky1,*, Katarina Magdechova ${ }^{2}$, Petr Nachtigall ${ }^{1}$, Stephan Schroder ${ }^{3}$, Pavlina Siroka ${ }^{1}$

${ }^{1}$ Department of Transport Technology and Control, Faculty of Transport Engineering, University of Pardubice, Czech Republic

${ }^{2}$ Wagon Service Travel, s.r.o., Bratislava, Slovakia

${ }^{3}$ Bahnzentrum Ingenieurburo, Syntrans GmbH, Germany

*E-mail of corresponding author: Jaromir.Siroky@upce.cz
} 
establishment of the Slovak Republic. Every development stage was aiming to make the process easier and ensure the continuity of particular activities in every area [7].

Authorising the types of railway vehicles has changed a lot since the Slovak Republic was established in 1993 [8]. It is possible to divide this process into several development stages that are described in detail in this paper. These are:

- authorising the types of railway vehicles in the years 1993-1996,

- $\quad$ authorising the types of railway vehicles in the years 1996-2009,

- $\quad$ authorising the types of railway vehicles in the years 2009-2014.

- $\quad$ authorising the types of railway vehicles in the years after the possible shift of competences to the EUAR (after 2020) [9-10].

In individual countries, authorising the types of railway vehicles and placing them in service is carried out by the authorising bodies or the NSA (National Safety Authority) in accordance with the Directive (EU) 2016/797 of the European Parliament and of the Council on the interoperability of the rail system within the European Union and also in accordance with particular related regulations, decisions and recommendations, and upon their transposition into the national legislation [11].

To analyse the current situation in the area of authorising the types of railway vehicles, the knowledge acquired at different conferences was used, as well as the available literature and studies from universities and research institutes. The analysis was carried out in six countries - Poland, Austria, Hungary, the Czech Republic, Spain and Germany [12-13].

Within the analysis, the legislation in the area of authorising the types of railway vehicles was analyzed and competences of particular bodies. With help of administrative outputs, an overview was made of registered vehicles in individual member states, notified bodies carried out in member states and types of vehicles registered in the European Register of Authorised Types of Vehicles (ERATV) [14-15].

The Transport Research Institute (Vyskumny ustav dopravny, a. s.) [16] has made a study called Implementation of interoperability of conventional railways of the Slovak Republic. The study describes the current interoperability and safety situation in terms of guidelines implementation, technical specifications for interoperability and assessing conformity of the individual components. To effectively address interoperability, an organisational proposal was prepared defining the key roles of state administration, railway undertakings, infrastructure manager and other stakeholders. The conformity assessment part describes the baselines of conformity assessment, requirements to be met by the authorised bodies, notification requirements and specific requirements in the process of assessing conformity of interoperability components and subsystems.

The study [17] addresses the use of TSIs as technical regulations, which are an integral part of authorising the types of railway vehicles and as such, the study was used mainly in the first part of the work in analysing individual TSIs related to railway vehicles. However, it only served as an aid as much of the data needed to be updated.

At the Department of Transport and Handling Machines of the Faculty of Mechanical Engineering of the University of Zilina [18], a computation tool for railway vehicle gauge was created with emphasis on interoperability. This program facilitates the work of manufacturers in using the TSIs and assessing conformity with TSIs. Its output is an input for the Notified Body (NoBo) and designated legal person (PPO) in terms of meeting gauge requirements which are provided to the authoriser of the type of railway vehicle based on this input.

In his speech on the international ERTMS conference, Guido [19-20] from the European Railway Agency specified the possible ways to ensure interoperability, analysing related legislation and the responsibilities of the individual bodies: NoBo, DeBo (designated bodies), etc. The knowledge is mainly used in the graphic representation of the hierarchy of legislation and distribution of competences, which is also used in creating the SW model.

The scientific work by Cech [21] focuses on benefits of introducing the interoperability into the European rail system. The author analyzed selected TSIs and focused on modelling the costs and benefits of interoperability, without a specific focus on railway vehicles though.

Jindra [22] is focused on proposing a complex tool for creation of the wagon load reference plans and for data exchange in accordance with the Telematics applications in freight transport TSI (TAF TSI) and analysed the TAF TSI in detail.

Type tests can have a significant impact on the general construction of the railway vehicle. As mentioned above, in manufacturing the railway vehicles, the manufacturer abides by the TSI. The vehicles also have to meet the TSI requirements in the "railway vehicles - noise" subsystem, setting out individual limits for railway vehicle noise [23]. Based on available sources of information, a suitable noise assessment tool can be the simulation using the TWINS software. This software assesses the noise sources, which can be different on the testing track and on the track in operation. The software must be updated in accordance with the amendments to noise legislation. Such update would significantly simplify the definition of manufacturing requirements and provide inputs for NoBos and authorized legal entity (PPOs) [24].

Commission Recommendation 2014/897/EU defines particular important elements in the area of authorising structural subsystems and placing vehicles in service. It is a broad guideline on how to proceed in this area in line with the provisions of Directive 2008/57/ES. There is no graphically shown procedure in the area of authorising the types of railway vehicles that are in accordance with technical specifications for interoperability (TSI) or are not in accordance with the TSI and their consequent placing in service. This was a part of the suggested methodology [25-26]. 
Individual scientific studies focus only on partial activities in the area of authorising the types of railway vehicles. They do not define the authorisation process as a complex of activities, they do not say how to simplify or speed it up, as a whole. To shorten the duration of the authorisation process, it was necessary to review and analyse particular problems that could emerge during the process. Because of this, it was inevitable to come up with operative solutions of problems that can occur. Not to foresee these problems could lead to extending the time necessary for authorising. Creating a convenient methodology for authorising the types of railway vehicles is an appropriate solution of these drawbacks, preventing the extension of the authorisation process.

\section{Methodology}

Based on the found differences and problems that could emerge during the process of authorising the types of railway vehicles, this paper outlines a methodology of authorising the types of railway vehicles as a supporting tool for setting up the SW model.

Apart from the basic methods (analysis, synthesis, brainstorming, etc.), other methods that are necessary for solving the stated problems were used, as well, [27].

The aim of the outlined methodology in the area of authorising the types of railway vehicles with the emphasis on using interoperability, new European regulations, rules and decisions, was to set up particular possible ways of carrying out the authorisation. The methodology is graphically shown using a development diagram and is afterwards reflected in an SW model, which is the main tool to minimise the administrative difficulties of the whole process.

The SW model can also be considered a tool to minimise the administrative problems of the whole process. It was created using the Visual Basic for Applications (VBA) macros.

The Microsoft Office package - Microsoft Excel with VBA editor have been applied by creating the Form. This decision was based on several criteria [28]:

1. MS Excel is part of the Microsoft Office package, which is currently installed on most computers used in administration.

2. MS Excel includes VBA editor, which is actually a programming language for Microsoft Office and this opens a lot more other options.

3. It is also possible to open other files from the MS Excel, which allows us to have a database in a separate file.

4. Within the VBA, it is possible to create files in MS Word.

5. Possibility to create pleasant and user-friendly graphical environment.

6. Possibility to create keys and sheets corresponding to a standard the user is familiar with from MS Windows.

\section{Programming}

The creation or generation of the Form and the final decision about authorising the type of railway vehicle were carried out by the VBA macros - using programming. Both global variables and functions were used.

\section{Form (Sheet)}

The main exercise book that is used by the user was named the "Form". It contains one page with the same name. The whole Form was named "The Form about Decision on Authorising the Railway Vehicle". It is preprogrammed and locked and the user can fill it in by the keys used for this purpose. In the first part, there are "Fill in" keys that are used to fill in information and a "Delete" key that is used to delete the filled in data. The latter is of course secured by the warning whether the Form should really be deleted. Filling in the Form can be postponed at any stage and particular steps can be filled in separately. For filling in the Form, sheets created in VBA are always used. There are programmed functions and automatic filling in to make the work for the user as easy as possible, effective and without mistakes. The Form adapts itself according to filled in data so the original and the final ones can look completely different. The outcome of the Form is a prescribed decision in the MS Word. Another advantage of the Form is that it is automatically saved in a file and as such, it is possible to go back to filling it in any time in the future [29].

\section{VBA}

Programming in VBA is divided into the following files: 1. Modules

It contains only one module (General), which includes global variables and functions for the work with MS Word and Outlook.

2. Microsoft Excel Objects

It contains one "Workbook", which also has a function that starts right after opening the Form. This function should serve to find the way to the file. It is a key for the next steps, allowing for opening the database and prescribed documents in Word.

It also contains one "Worksheet", which includes:

- a function for opening the database,

- a function that controls whether particular cells in the Form have not been changed and based on these changes, it saves the Form with a new name or adapts the Form according to filled in data (shows and hides parts of the Form),

- it also contains serving functions that are activated by pressing particular keys. Note: these functions open further particular forms and functions according to the key pressed.

\section{Forms}

There are 15 forms that are used to fill in the Form. Those forms are activated automatically or after pressing a key.

Every form consists of two parts:

- "Object", which is its graphic draft,

- "Code“, which includes the source code for a particular "Object". The "Code" contains functions that are 


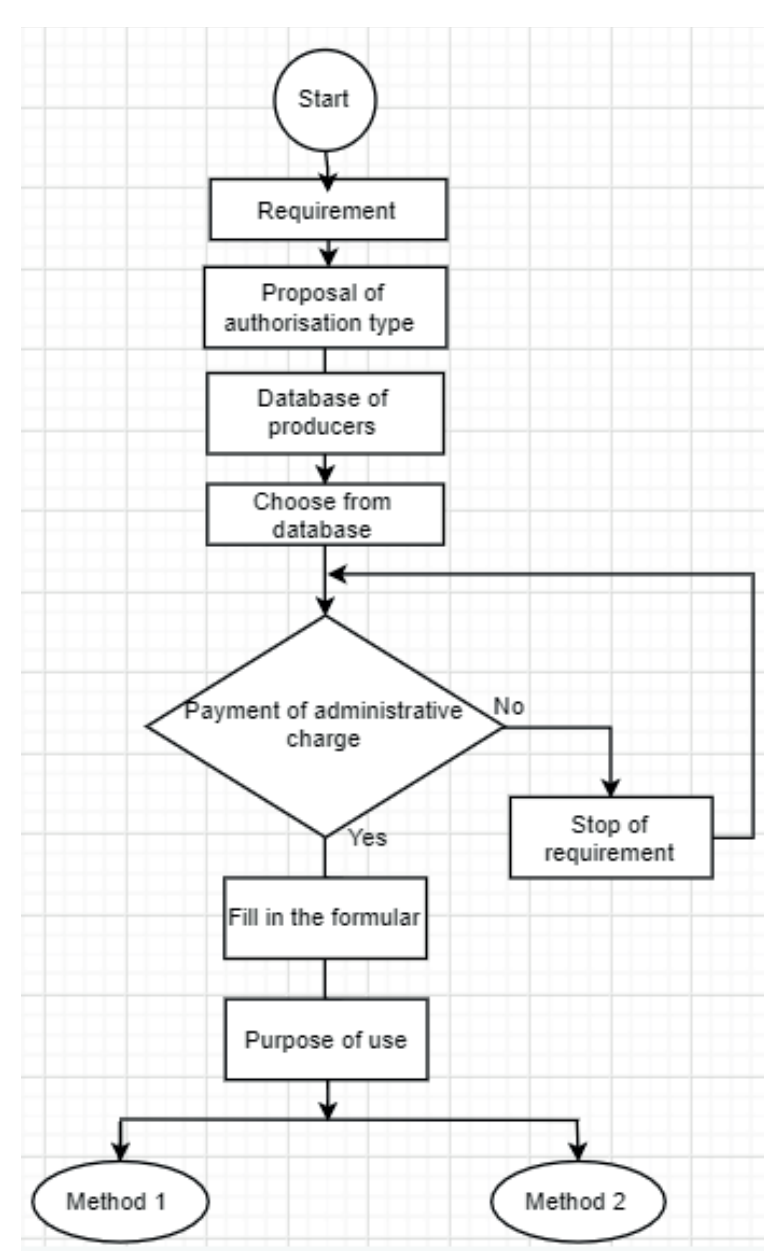

Figure 1 Basis for the VBA I

activated when opening a particular form (it serves for the starting initialisation and filling in the form based on the data already stated in the form). It also includes functions that are activated while filling in particular cells (these serve mainly to ensure that the data have been filled correctly or to make sure that data have been filled automatically). Functions that are shown after pressing a button mainly serve to open other forms or to close the form.

Parts in a graphic interface for the Form were set up using "Properties" for particular elements. All the functions and methods used when programming are described in the Help Excel - VBA (option displayed after pressing F1 when the cursor is on this command).

Filling in the Form leads to generating a complete decision that is filled in with the data from the database, as well.

As shown below in Figures 1 and 2, the process starts with submitting a request for authorising the type of a railway vehicle. At first, it is necessary to state or decide whether it will be authorisation of the type of a railway vehicle, its modernisation or innovation. Sending the request electronically will lead to a faster submission and the authorising body can thus start the process of its evaluation sooner. Afterwards, the authorising body can find an applicant in a database of producers, or it can generate it for the next use. The database is, or will be, constantly updated according to the needs of the authorising body, which will speed up the process of decision making, where the date will be automatically reflected.

After setting the purpose of use, it is possible to state which way the authorisation will go, or which method will be used.

In method 1, the authorisation according to specifications of regulations, mainly with the national legislation, is considered. That is why in this methodology the fact that the user will have an updated version of the regulation is considered. After meeting the requirements, it is possible to proceed to generating the decision itself.

The second version of authorisation is verifying the compliance with the TSI. Here it is necessary to get a review from the Notified Body (NoBo). That is why the option of connecting to NoBo is considered. The system also takes into account the possibility of submitting information about the type of vehicle, range of vehicle, power, etc.

Figure 3 shows the graphic representation and programming of the Form. 

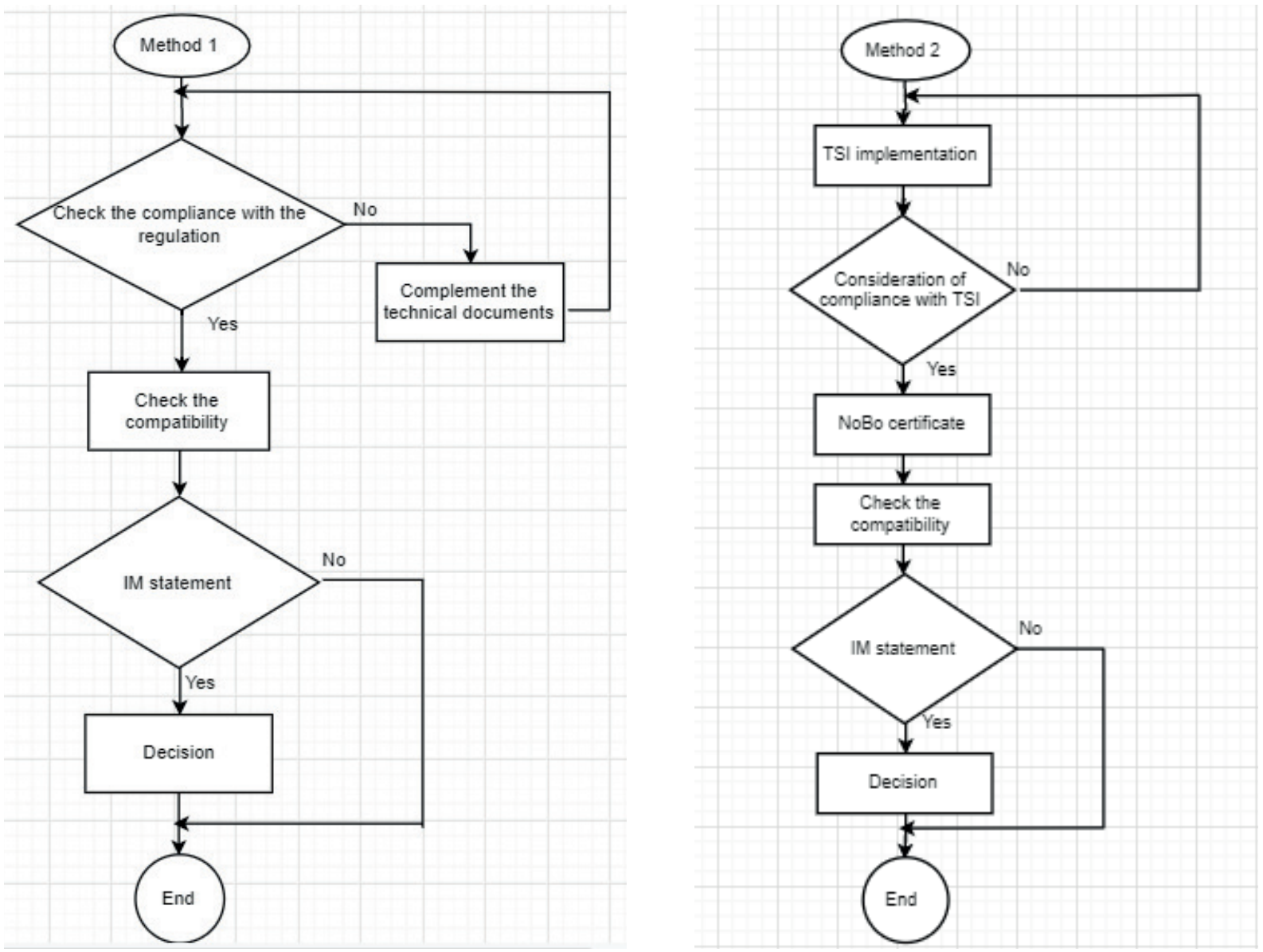

Figure 2 Basis for the VBA for methods I and II

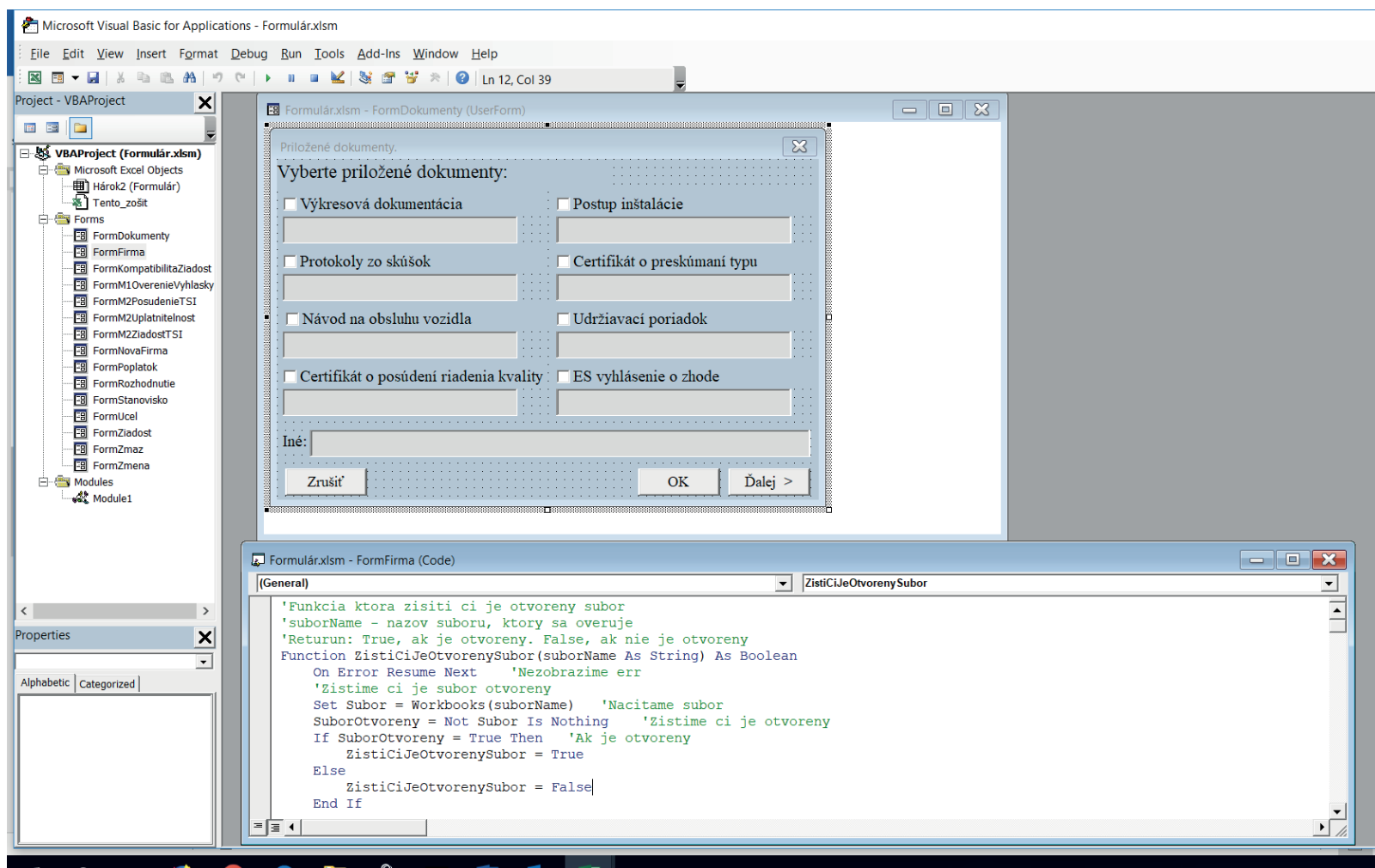

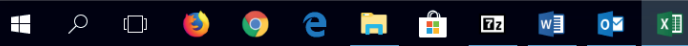




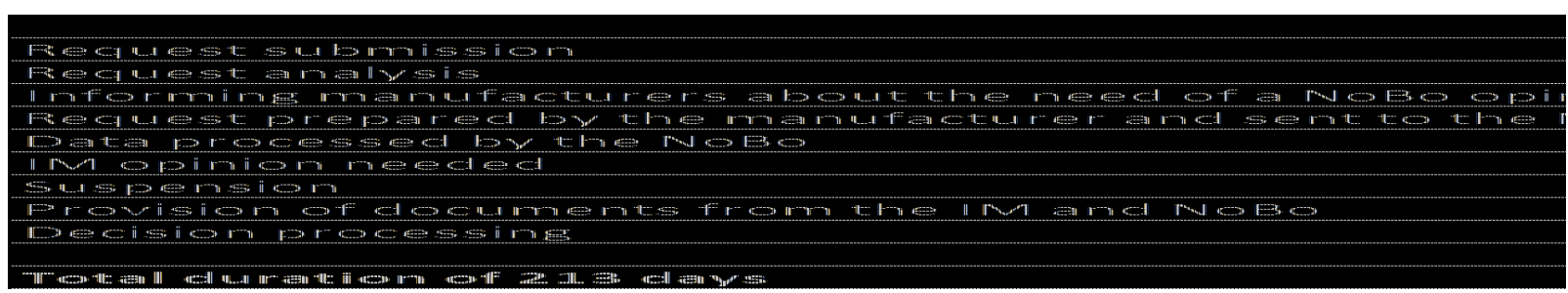

Figure 4 The Gantt chart of the ETCS L1 duration

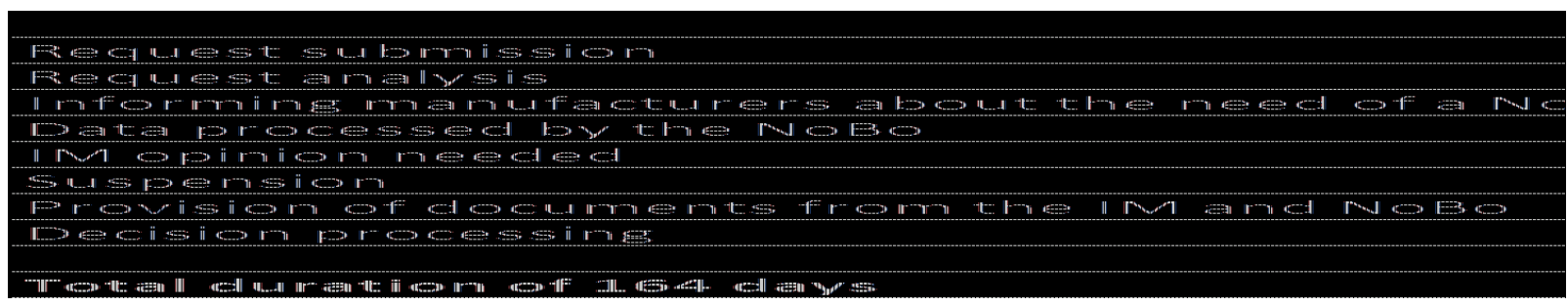

Figure 5 The Gantt chart of the ETCS L1 using SW

Table 1 Conclusion of verifications of cases 1-3

\begin{tabular}{ccccc}
\hline Case & Without SW [working days] & With SW [working days] & Saving [working days] & Saving [\%] \\
\hline C1 & 213 & 164 & 49 & 23.00 \\
C2 & 122 & 85 & 37 & 30.33 \\
C3 & 153 & 99 & 54 & 35.29 \\
\hline
\end{tabular}

\section{Achieved results}

The methodology of authorising the railway vehicles and its usage was verified by the use of simulation directly in MS Excel with use of the VBA macros. The aim was to provide an estimate of duration of the authorisation process of the railway vehicles or different cases within this process. The Gantt chart was used to show duration of particular activities.

Case 1: Installing a mobile part of European Train Control System Line 1 into an electrical multiple unit class 671 type 214

The total duration of the process allowing an essential change by installing the ETCS L1 into the electric multiple unit (EMJ) class 671 type 214 was 213 working days. The total duration of the process allowing an essential change by installing EMJ class 671 type 214 into ETCS L1 into a vehicle with the use of SW was 164 working days. The process of authorisation with use of the system was shortened as shown below (Figure 4). The percentage saving was $23 \%$. Creating a prototype board was not considered. Even with this, one can see that the duration of the process decreased significantly. Duration of authorisation is therefore individual and depends on the particular case.

Figure 4 shows the authorisation of an essential change of a train protection system and duration of the individual processes without using the system. The total duration of the authorisation process for 2014 was 213 working days. As can be seen from the Gantt chart, it was necessary to suspend the process in September due to the absence of opinion of the infrastructure manager and the NoBo. The process was suspended due to the absence of documents to be provided by the NoBo and to serve as an input for the infrastructure manager.

Using the SW model shortened the authorisation process by 49 days. If the prototype commission was established as early as in the preparatory phase, i.e. before the submission of the authorisation request, the process could be shortened for duration of the suspension (nearly one month). The benefit of using the system is the streamlining of data entering and processing (Figure 5).

\section{Case 2: Authorising the three-system electrical} locomotive class 381 type $109 \mathrm{E} 2$

The total duration of the authorisation process of the locomotive class 381 type 109 E2 was 122 working days. The total net duration of the authorisation process with use of the SW system was 64 working days. To make this time even more effective, a prototype commission was established, which allowed for solving several possible inconsistencies even before submitting the application for authorisation. The process of authorisation with use of the system was shortened as shown below (Table 1). The percentage saving of the authorisation process, including duration of the prototype commission, was $30.33 \%$. The prototype commission markedly influences the net duration of the authorisation process. As already mentioned, the time saving is very individual. A reduction in duration can be secured by establishing the prototype commission. 
Case 3: Authorising the diesel unit class 861 type VR - 24 - 2010 - DMJ

The total duration of the authorisation process of DMJ class 861 type VR - 24 - 2010 - DMJ was 153 working days. The total net duration of the authorisation process with use of the SW was 40 working days. To make this time even more effective, a prototype commission was established, which allowed for solving some of the inconsistencies even before submitting the application for authorisation. The process of authorising with use of the system was shortened as shown below (Table 1). The percentage saving of the authorisation process, including the duration of the prototype commission, was $35.29 \%$. As mentioned before, the time saving is very individual and changes with each case. To further reduce the duration, it is also possible to establish the prototype commission, which can influence the duration of the authorisation process.

\section{Discussion}

Based on the verification of the outlined methodology of authorising the types of railway vehicles with the use of the SW system, one can conclude that duration of the authorisation process is very individual and changes with each case.

In verifying process the stated hypothesis in practice in the first case - implementing a mobile part ETCS L1 into an electric multiple unit class 671 type 214 - the hypothesis was not confirmed. Duration of the authorisation decreased by $23 \%$. However, even this result is a significant shortening.

In the second case - authorising the three-system of an electric locomotive class 381 type 109 E2 - duration of authorisation was significantly shorter. It is very important to note that a prototype commission was established, which can directly influence the net duration of the authorisation process. Since the duration was $30.33 \%$ shorter, the hypothesis was confirmed.

The third case - approving the diesel unit class 861 type VR - 24 - 2010 - DMJ - also confirmed the stated hypothesis. A prototype commission was established in this case as well, which influenced the total duration of authorisation to such an extent that the saving was $35.29 \%$.

During the verification of the particular cases, simulation, stated estimation of duration of the particular stages (mostly when using the SW system) were used as well as the method of brainstorming.
Durations were estimated based on discussions with the representatives of the authorising bodies or related subjects.

\section{Conclusions}

Complex mapping and summarising of the current situation in the authorisation process of the types of railway vehicles, both at home and abroad is taking a part of the paper. It gives information on the applicable legislation related to train railway vehicles. It also provides an overview of these matters to both the wide public and the academic sphere.

The methodology, which is based on an SW model, makes the authorisation process significantly easier and faster. It provides clear evidence and ensures more effective cooperation. It also brings the possibility of using the new modern SW tools in the authorisation process. Most of the communication happens online, including the issuing of the particular documents, which are a basis for the decision on the authorisation. Therefore, it saves postage costs, as well as office material.

International application of outlined methodology is possible. It is possible to change it according to individual needs. After adding further functions, it can be adjusted to needs of the EUAR and can speed up the communication and information exchange between the EUAR and national authorisation bodies. This can be ensured by a contact treaty between the EUAR and NSA. The aim is to use the SW model in accordance with the European legislation. This would result in reducing both duration and costs of the authorisation process.

The methodology is an asset also to producers and owners of the railway vehicles, as well as to the wide public. This methodology would bring a faster exchange of information, time and cost savings and a possibility of an operative solution of possible problems.

\section{Acknowledgement}

The work was supported by the ERDF/ESF "Project PosiTrans - University of Pardubice cooperation and application sphere in application oriented research of localization, detection and simulation systems for transport processes" (No. CZ.02.1.01/0.0/0.0/17_049/0008394).

\section{References}

[1] MAGDECHOVA, K. The analysis of the development of types of authorisation processes for different railway vehicles in Slovak Republic (in Slovak). In: International conference Horizons of Railway Transport 2014 : proceedings. 2014. ISBN 978-80-554-0918-4, p. 140-149.

[2] MAGDECHOVA, K., NACHTIGALL, P. Changes in types of authorisation processes for different railway vehicles (in Slovak). In: International conference Horizons of Railway Transport 2013 : proceedings. 2013. ISBN 978-80-554-0764-7, p. 242-248. 
[3] European Commission, DG Move. Report on the work performed by the task force on railway vehicles authorisation. Brussel, 2012.

[4] EBA, Schweizerische Eidgenossenschaft, ANSF, BMVIT, HETI. Cross acceptance and corridor guideline. In: Control Command and Railway Communication Conference 2012 : proceedings. 2012.

[5] Reming Consult, a. s., Sudop Praha, a. s., AM Sudop spol. s. r. o. Technical and economic study for the preparation and implementation of ERTMS on Corridor E (in Slovak). 2010.

[6] RARDIACA, F., LO YACONO, L. Authorisation type of vehicles. Final report. 2013.

[7] IHNAT, P. Railway interoperability in EU (in Slovak). Railway transport and logistics. 2006, p. 103-109. ISSN 1336-7493.

[8] DANIS, J., DOLINAYOVA, A., CERNA, L., ZITRICKY, V. Impact of the economic situation in the Slovak Republic on performances of railway transport. Periodica Polytechnica Transportation Engineering [online]. 2019, 47(2), p. 118-123. ISSN 0303-7800, eISSN 1587-3811. Available from: https://doi.org/10.3311/PPtr.11185

[9] Commission Decision No. 2011/314/EU concerning the technical specification for interoperability "relating to the operation and traffic management" subsystem of the trans - European conventional rail system [online]. Brussel, 2011. Available from: https://eur-lex.europa.eu/LexUriServ/LexUriServ.do?uri=OJ:L:2011:144:0001:0112:EN:PDF

[10] Commission Decision No. 2012/757/EU concerning the technical specification for interoperability relating to the "operation and traffic management" subsystem of the rail system in the European Union and amending Decision 2007/756/EC [online]. Brussel, 2012. Available from: https://eur-lex.europa.eu/LexUriServ/LexUriServ. do?uri=OJ:L:2012:345:0001:0076:EN:PDF

[11] GHAZEL, M. Formalizing a subset of ERTMS/ETCS specifications for verifications purposes. Transportation Research Part C: Emerging Technologies [online]. 2014, 42, p. 60-75. ISSN 0968-090X, eISSN 1879-2359. Available from: https://doi.org/10.1016/j.trc.2014.02.002

[12] GASPARIK, J., SIROKY, J., PECENY, L., HALAS, M. Methodology for assessing the quality of rail connections on the network. Communications: Scientific Letters of the University of Zilina [online]. 2014, 16(2), p. 25-30. ISSN 1335-4205, eISSN 2585-7878. Available from: http://komunikacie.uniza.sk/index.php/communications/article/ view/503

[13] KAMPF, R., GASPARIK, J., KUDLACKOVA, N. Application of different forms of transport in relation to the process of transport user value creation. Periodica Polytechnica Transportation Engineering [online]. 2012, 40(2), p. 71-75. ISSN 0303-7800, eISSN 1587-3811. Available from: https://doi.org/10.3311/pp.tr.2012-2.05

[14] ERA, EK. Progress on the vehicle authorisation task force recommendations. In: EC ERA Workshop on Vehicle Authorisation: proceedings. 2013.

[15] LAVOGIEZ, H., DECHAMPS, J.-M., ARDIACA, F. Type of vehicle. In: ERA Workshop on Vehicle Authorisation : proceedings. 2012.

[16] VUD Transport Research Institute. Implementation of interoperability in Slovak Railway (in Slovak). Final report. 2005.

[17] BIERLEIN, H. Certification and placing in service. In: ERTMS World Conference : proceedings. [online]. 2012. Available from: https://www.uic.org/com/uic-e-news/274/article/10th-uic-ertms-world-conference-2648.

[18] BACISIN, M., FUSATY, M., PALUCH, J. Calculation of the gauge of railway vehicles with regard to interoperability (in Slovak). Railway transport and logistics. 2012, p. 10-15. ISSN 1336-7943.

[19] GUIDO, P. Specifications for interoperability. In: ERTMS World Conference : proceedings [online]. 2012. Available from: https://www.uic.org/com/uic-e-news/274/article/10th-uic-ertms-world-conference-2648

[20] GUIDO, P. ERTMS baselines. In: UIC ERTMS World Conference : proceedings [online]. 2014. Available from: https://uic.org/com/uic-e-news/366/article/11th-uic-ertms-world-conference?page=modal_enews

[21] CECH, R. Costs and benefits analysis of interoperability implementation (in Czech). Thesis DFJP. University of Pardubice. 2012.

[22] JINDRA, P. System implementation of operational interoperability in freight railway transportation (in Czech). Thesis DFJP. University of Pardubice. 2010.

[23] FRID, A., LETH, S., HOGSTROM, C., FARM, J. Noise control design of railway vehicles - impact of new legislation. Journal of Sound and Vibration [online]. 2006, 293(3), p. 910-920. ISSN 0022-460X. Available from: https://doi.org/10.1016/j.jsv.2005.12.014

[24] LOCKETT, R. The vehicle authorisation process. In: ERTMS World Conference : proceedings. [online]. 2012. Available from: https://www.uic.org/com/uic-e-news/274/article/10th-uic-ertms-world-conference-2648

[25] GASPARIK, J., MAJERCAK, J., SIROKY, J., ABRAMOVIC, B., MESKO, P., NACHTIGALL, P., ZITRICKY, V. Railway traffic operation. Zilina: University of Zilina, 2017. ISBN 978-80-554-1281-8.

[26] MYDIA, S., THOTTAPPILLIL, R.: An overview of electromagnetic compatibility challenges in European Rail Traffic Management System. Transportation Research Part C: Emerging Technologies [online]. 2008, 16(5), p. 515-534. ISSN 0968-090X, eISSN 1879-2359. Available from: https://doi.org/10.1016/j.trc.2007.11.001

[27] PAHOLOK, I. Simulation as a scientific method (in Slovak). E - LOGOS Electronic Journal for Philosophy. 2008, 1, p. 1-19. ISSN 1211-0442. 
[28] SIROKY, J., CEMPIREK, V., GASPARIK, J. Transport technology and control. Brno: Tribun EU, 2014. ISBN 978-80-263-0711-2.

[29] TOURNIER, N. T., DRILLER, J. The national legal framework (DE). Technical document (reference document part 3) [online]. 2014. Available from: https://rdd.era.europa.eu/rdd/documents/nlf/NLF\%20DE\%201.6.1\%20for\%20 publication.pdf 